\title{
Group decision making process for RFI D-based system selection using fuzzy TOPSIS approach
}

\author{
Yahia Zare Mehrjerdi \\ Department of Industrial Engineering, Yazd University, I ran \\ Correspondence: Yahia Zare Mehrjerdi. Address: Department of Industrial Engineering, Yazd University, Iran. Email: \\ Yazm2000@yahoo.com.
}

Received: June 11, 2012

Accepted: August 27, 2012

Online Published: March 21, 2013

DOI : 10.5430/air.v2n3p1

URL: http://dx.doi.org/10.5430/air.v2n3p1

\begin{abstract}
The purpose of this article is twofold: first to introduce a multi attribute decision making model for radio frequency identification system consisting of four main criteria and five alternatives, and second to develop and solve the proposed fuzzy TOPSIS problem. Author presented an effective fuzzy multi-criteria method based upon the fuzzy model and the concepts of positive ideal and negative ideal solution points for solving problems with a group of multi decision makers. The fuzzy sets concepts are used to evaluate the performance of alternatives and the importance of criteria. The TOPSIS model used in this article is able to grasp the ambiguity exists in the utilized information and the fuzziness appears in the human judgments and preferences. TOPSIS technique can easily produce satisfactory results, and hence stimulates creativity and the invention for developing new methods and alternative approaches. This article is a very useful source of information both for radio frequency identification and multi attribute decision making using fuzzy TOPSIS methodology.
\end{abstract}

\section{Key words}

RFID based systems, System selection, Group decision making, TOPSIS, Fuzzy TOPSIS

\section{I ntroduction}

Fleisch and Tellkamp ${ }^{[1]}$ reported that shrinkage accounted for $2 \%-4 \%$ of sales in the US retail industry in 2001. Atali et al. ${ }^{[2]}$ distinguish in their paper between three main sources of inventory discrepancies which are not taken into account in the classical inventory models: (1) Shrinkage, (2) Misplacement of products, and (3) Transaction errors. Lee and Ozer ${ }^{[3]}$ reported that between $10 \%$ and $66 \%$ of the original shrinkage observed is reduced after implementing Radio Frequency Identification (RFID) technologies. De Kok et al. ${ }^{[4]}$ have developed a mathematical model for comparing the situation with RFID and the one without RFID in terms of costs. Using their model it was possible for them to obtain an exact analytical expression for deriving break-even prices of an RFID tag. It turned out that those break-even prices were highly related with the value of the items that was lost, the shrinkage fraction and the remaining shrinkage after implementing RFID. These same authors proposed a simple rough-cut approximation to determine the maximum amount of money a manager should be willing to invest in RFID technology.

All these point to this reality that an increasing demands for security and safety, for our food, health, medication, and tracing and tracking transporting goods, are out there. These are the needs of every people of every society and the companies that produce goods and those that transmit them to their customers and those that use them as the final 
consumers. In this same line of taught, there is a need for complete documentations of food products, from field to customer as was highlighted by Thysen ${ }^{[5]}$.

RFID is a method for sending and receiving data without any contacts occurs between the interrogators and tags using electromagnetic waves ${ }^{[6]}$. RFID tags can hold more information than data carrier systems such as barcode system. An RFID system is comprised of tags, a reader that can read data from the tag, antenna and the hardware and software. The main purpose for setting up an RFID system is to collect desirable data from a moving object or a fixed one. Although, there is piling news against the security of this technology and the privacy problem recent expert reports indicate that, billions RFID tags are produced and implemented all around the world. RFID has been identified as one of the ten greatest contributory technologies of the 21st century. Companies lined up to use RFID and employing experts to improve the efficiency of their operations in order to gain competitive advantages over time. Manufacturers can use RFID solutions to reduce operating costs through decreasing the labor costs, claims, and returns. This will help them to increase the operating income. They also can reduce the working capital by enabling reductions in inventory and lowering the inventory write-off from the return goods and those items that are un-saleable at the end. Main benefits of RFID can be listed as stated by Hou and Huang ${ }^{[7]}$ and Zare Mehrjerdi ${ }^{[8]}$ :

1) Improving the speed and accuracy for tracking pallets, boxes and containers

2) Helping to reduce stock levels

3) Helping to reduce operating costs

4) Improving the management of inventory

5) Improving efficiencies in WIP reporting

6) Improving inventory visibility to feed JIT systems

Although RFID technology has been around since 1960 the use of RFID in supply chain management is new. The world largest retailers, including Wal-Mart in the United States, Metro Group in Germany, Marks \& Spencer in the United Kingdom mandated the use of RFID in tracking supplies ${ }^{[9]}$. In 2004, the US DoD also became another strong supporter of this technology. It was March 2005 that more than 104 Wal-Mart stores have been equipped with the RFID systems. By that time 36 of Sam's Clubs and three of Wal-Mart's distribution centers ${ }^{[10,11]}$ were also equipped with this technology. By 2006, Insight forecasted that tagging will be well on its way to becoming common place within supply chains, including among smaller retailers and suppliers, with an expected tag price of 1 to 2 US cents. Insight Research expected that tagging at the item level to be widespread, virtually replacing bar coding. The pace of RFID adoption is estimated by Collins ${ }^{[12,13]}$ and the risk of RFID was studied by Rappold ${ }^{[14]}$.

A study conducted by Lee et al. ${ }^{[15]}$, designing and development of logistics workflow systems for demand management with RFID, authors show that RFID can enhance the responsiveness of the logistics workflow. In a study conducted by KO et al. ${ }^{[16]}$ authors have dealt with product tracking problem for the large scale supply chain with many nodes such as the international supply chain with import and export nodes. Szmerekovsky et al. ${ }^{[17]}$ have studied the question that whether it is possible for the manufacturer as well as the retailer to drive economic benefits from item-level RFID. Ustundag et al ${ }^{[18]}$ have developed a fuzzy rule-based system for the economic analysis of RFID investments. Through that authors were able to propose a procedure for fair evaluation of the savings associated with the increasing performance and investment costs. As the application of the RFID gets more acceptability by the users the construction of such systems gets more importance. Various countries have started to use RFID in different forms and shapes. RFID is used to develop intelligent highways ${ }^{[19]}$, distribute products ${ }^{[20]}$, and transport construction materials ${ }^{[21]}$. It is used in manufacturing to monitor the factory level ${ }^{[22]}$, US postal services ${ }^{[23]}$, agriculture and food industry ${ }^{[24]}$, supply chain management ${ }^{[25,26]}$, service sector ${ }^{[27]}$, product design ${ }^{[28]}$, managing restaurant ${ }^{[29]}$, supply chain systems with mobile monitoring capability ${ }^{[29-31]}$, monitoring patients with diet problem ${ }^{[32]}$, pharmacy industry ${ }^{[33]}$, for hospital social impacts assessment ${ }^{[34]}$, logistic ${ }^{[35,36]}$, in pharmaceutical industry, and for monitoring and tracking live animals ${ }^{[37]}$. 
Using the concepts of fuzzy sets theory and linguistic values, author presents a systematic decision process for selecting appropriate RFID-based system for an organization wishing to expand into RFID technology. The proposed methodology is based upon the TOPSIS method under fuzzy environment. This is due to the fact that RFID adoption is a risky business and demands a way of dealing with vagueness and uncertainty. The decision criteria are determined through the review of literature. The rest of this paper is structured as follows: section 2 introduces the research goals while section 3 discusses the selection criteria for evaluation of RFID. Multiple criteria decision making is discussed in section 4. Fuzzy sets and arithmetic operations is the topic of section 5. TOPSIS algorithm is discussed in section 6. A case study is presented in section 7. The discussion and conclusion is given in section 8 .

\section{Research goals}

This research presents a multi attribute decision making methodology for selecting the best possible service system among a list of service systems that a business can offer to its customers over time. The objectives of this research are as follows:

1) To identify various RFID-based system services suitable for small businesses in general

2) To determine the lists of criterions best suited for the model evaluation

3) To study and describe a fuzzy TOPSIS methodology for solving the problem

4) To provide data for a case study taking the inputs from a group of decision makers

5) To solve the case and analyze the results.

\section{Selection criteria for evaluation of RFID}

Evaluating RFID decisions is not a well defined or structured problem in literature specially that RFID is a new technology and at the edge of its development and expansion. To the best of this author's knowledge and the evidence from the literature, no such work has been attempted prior to this in relation to RFID. Hence, this research will make a good contribution to the literature of RFID and the expansion of the domain of application of Multi Attribute Decision making (MADM) tools such as TOPSIS. To study this problem using TOPSIS, both positive (benefit type) and negative (cost type) criterions that can be used to evaluate alternatives must be considered in the decision process. Since benefits and risks of RFID decisions are intangible in nature different decision makers may assign the benefits and risks of RFID decisions and their importance differently. Therefore, these kinds of decision criteria can only be measured subjectively. Often in multi criterion decision making problems, data are imprecise and fuzzy so it requires different treatment, modeling, and solution methodology to gain a true understanding of the situation. On the other hand, classical Multi Criteria Decision Making (MCDM) methods that assume all scores of alternatives and weights of attributes values are crisp numbers, cannot effectively handle problems with such imprecise information. Therefore, an appropriate evaluation methodology and evaluation criteria have to be identified.

\section{Multiple criteria decision making}

Perhaps the single most important decision faced by management when dealing with multiple objectives is the selection of an appropriate solution, which optimizes the proposed criteria simultaneously. Therefore, it is hardly surprising that much of the literature in operations research focuses on the Multiple Objective Decision Making (MODM) Problems. The decision space used in the MODM is a continuous one and the proposed model can be solved with mathematical programming techniques. An alternative could be described whether in terms of its attributes or in terms of the attainment of the decision maker's objectives ${ }^{[38,39]}$. A Multi Attribute Decision making model deals with the problem of choosing an option from a set of alternatives which are characterized in terms of their attributes. It is a qualitative approach due to the existence of criteria subjectivity. The aim of the MADM is to obtain the optimum alternative that has the highest degree of satisfaction for all of the relevant attributes. 
Modeling real world problems with crisp values under many conditions is inadequate because human judgment and preference are often ambiguous and cannot be estimated with exact numerical values ${ }^{[40-42]}$. There are ways to rank competitive alternatives but ranking competing alternatives in terms of their overall performance with respect to some criterions in fuzzy environment is made possible by the use of fuzzy TOPSIS methodology. TOPSIS treats a multi attribute decision making problem with $\mathrm{m}$ alternatives as a geometric system with $\mathrm{m}$ points in the $\mathrm{n}$-dimensional space ${ }^{[43]}$. The ranking of alternatives in TOPSIS is based upon 'the relative similarity to the ideal solution point', which avoids from the situation of having same similarity to both ideal and negative ideal solutions points.

During the years, many authors such as Chen ${ }^{[40]}$; Negi et al. ${ }^{[44]}$, Chen et al. ${ }^{[41]}$; Chen and Hwang ${ }^{[45]}$; Chen and Tzeng ${ }^{[46]}$; Jahanshahloo, Hosseinzadeh Lotfi, and Izadikhah ${ }^{[47]}$; Liang ${ }^{[48]}$; Wang and Elhag ${ }^{[49]}$; Wang and Lee ${ }^{[50]}$; Wang, Luo, and Hua ${ }^{[51]}$; Yeh, Deng, and Chang ${ }^{[52]}$; and Yeh and Deng ${ }^{[53]}$, and Zare Mehrjerdi ${ }^{[54,55]}$ have contributed new materials on the development, extensions and applications of TOPSIS since its early development in 1981. Its general extension for group decision making problems under fuzzy environment was published by Chen ${ }^{[40]}$. In 2007, Kahraman and his research team proposed a hierarchical fuzzy TOPSIS method that has ability to consider the hierarchy among the attributes and alternatives. This method provides greater superiority to classical fuzzy TOPSIS methods ${ }^{[43]}$. Other researchers have employed TOPSIS and applied that to areas as such as company financial ratios comparison ${ }^{[56]}$, facility location selection

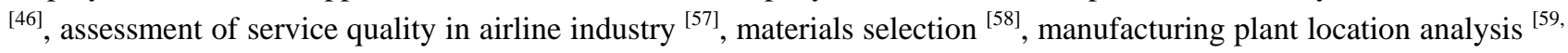
${ }^{60]}$, and Robot selection ${ }^{[61]}$, to mention a few.

\section{Fuzzy set and arithmatics operations}

Due to the fact that crisp data are inadequate for modeling the real life situations in multi criteria decision making, we apply linguistic variables to specifically describe the degrees of a criterion. In order to facilitate the making of subjective assessment by the decision makers (DM) using fuzzy numbers, two sets of linguistic terms are used for assessing criteria weights and performance rating on each qualitative criterion respectively. A linguistic variable is a variable which apply words or sentences in a natural or artificial language to describe its degree of value, and we use this kind of expression to compare each criteria by linguistic variables in a fuzzy environment as "extremely important", "very important”, “important”, “very unimportant”, and “'extremely unimportant” with respect to a fuzzy five level scale [62].

A real fuzzy number $\mathrm{A}$ is described as a fuzzy subset of the real number $\mathrm{R}$ with member function $f_{\mathrm{A}}$ that represents uncertainty. A membership function is defined from universe of discourse to $[0,1]$ (see Figure 1). A triangular fuzzy number can be defined as a triplet (a, b, c). Therefore, a membership function of the fuzzy number A is defined as

$$
f_{A}= \begin{cases}0, & x \leqslant a \\ \frac{x-a}{b-a}, & a \leqslant x \leqslant b \\ \frac{c-x}{c-b}, & b \leqslant x \leqslant c \\ 0, & x \leqslant c\end{cases}
$$

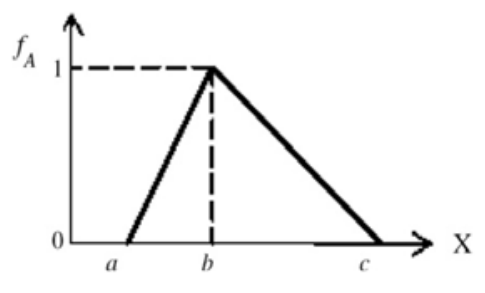

Figure 1. A triangular fuzzy number

Using this representation, we can do arithmetic operations on fuzzy numbers very simple and quick. With the notations given above the arithmetic operations of $(+),(-),(x)$, and $(\div)$ on fuzzy numbers are defined as follows:

$$
\left(a_{1}, b_{1}, c_{1}\right)(+)\left(a_{2}, b_{2}, c_{2}\right)=\left(a_{1}+a_{2}, b_{1}+b_{2}, c_{1}+c_{2}\right)
$$




$$
\begin{gathered}
\left(a_{1}, b_{1}, c_{1}\right)(-)\left(a_{2}, b_{2}, c_{2}\right)=\left(a_{1}-c_{2}, b_{1}-b_{2}, c_{1}+a_{2}\right) \\
\left(a_{1}, b_{1}, c_{1}\right)(x)\left(a_{2}, b_{2}, c_{2}\right)=\left(a_{1} x a_{2}, b_{1} x b_{2}, c_{1} \times c_{2}\right) \\
\left(a_{1}, b_{1}, c_{1}\right)(\div)\left(a_{2}, b_{2}, c_{2}\right)=\left(a_{1} \div c_{2}, b_{1} \div b_{2}, c_{1} \div a_{2}\right)
\end{gathered}
$$

The inversion of a fuzzy number and the multiplication of constant times a fuzzy number are done according to following formula:

$$
\begin{aligned}
& \left(a_{1}, b_{1}, c_{1}\right)^{-1}=\left(\frac{1}{c_{1}}, \frac{1}{b_{1}}, \frac{1}{a_{1}}\right) \\
& k x\left(a_{1}, b_{1}, c_{1}\right)=\left(k a_{1}, k b_{1}, k c_{1}\right)
\end{aligned}
$$

The distance between fuzzy numbers of $\left(a_{1}, b_{1}, c_{1}\right)$ and $\left(a_{2}, b_{2}, c_{2}\right)$ is calculated as below ${ }^{[40] \text { : }}$

$$
d\left(A_{1}, A_{2}\right)=\sqrt{(1 / 3)\left[\left(a_{1}-a_{2}\right)^{2}+\left(b_{1}-b_{2}\right)^{2}+\left(c_{1}-c_{2}\right)^{2}\right]}
$$

\section{Fuzzy TOPSI S algorithm}

TOPSIS, a linear weighting technique, was developed by Hwang and Yoon ${ }^{[63]}$ in its crisp form and then expanded by Chen and Hwang in $1992^{[45]}$. The foundation of TOPSIS is grounded on the logic of defining the positive ideal solution and the negative ideal solution points. Fuzzy TOPSIS algorithm is comprised of seven steps as are discussed one by one below.

\section{Step 1: Decision Matrix and Weight development}

The very first step of TOPSIS algorithm is the determination of the decision matrix. This matrix has m rows and $n$ columns, where $\mathrm{m}$ represents the number of alternatives to be ranked, $A_{i}(\mathrm{i}=1, . ., \mathrm{m})$, and $\mathrm{n}$ represents the number of criterions that based on that the ranking will be based on $C_{j}(\mathrm{j}=1, \ldots, \mathrm{n})$. In the model, it is assumed that there are $\mathrm{K}$ decision makers that subjectively assess the weighting vector of $W=\left(w_{1}, \ldots, w_{n}\right)$ and the decision matrix $\mathrm{D}=\left\{x_{i j}\right.$, $\mathrm{i}$ $=1,2, \ldots, m$; and $\mathrm{j}=1,2, \ldots, \mathrm{n}\}$, using the linguistic terms described in table 1 .

Table 1. Fuzzy linguistic terms and corresponding fuzzy numbers for each criterion

\begin{tabular}{lll}
\hline Importance & Abbreviation & Fuzzy Number \\
\hline Very low & VL & $(0,0,0.2)$ \\
Low & $\mathrm{L}$ & $(0.05,0.2,0.35)$ \\
Medium low & $\mathrm{ML}$ & $(0.2,0.35,0.5)$ \\
Medium & $\mathrm{M}$ & $(0.35,0.5,0.65)$ \\
Medium high & $\mathrm{MH}$ & $(0.5,0.65,0.8)$ \\
High & $\mathrm{H}$ & $(0.65,0.8,0.95)$ \\
Very high & $\mathrm{VH}$ & $(0.8,1,1)$ \\
\hline
\end{tabular}

Table 2 provides the fuzzy linguistic terms and corresponding fuzzy numbers for each alternative. 
Table 2. Fuzzy linguistic terms and corresponding fuzzy numbers for each alternative

\begin{tabular}{lll}
\hline Importance & Abbreviation & Fuzzy Number \\
\hline Very poor & VP & $(0,0,0.2)$ \\
Poor & P & $(0.05,0.2,0.35)$ \\
Medium poor & MP & $(0.2,0.35,0.5)$ \\
Fair & F & $(0.35,0.5,0.65)$ \\
Medium good & MG & $(0.5,0.65,0.8)$ \\
Good & G & $(0.65,0.8,0.95)$ \\
Very good & VG & $(0.8,1,1)$ \\
\hline
\end{tabular}

Taking alternatives $A_{i}(\mathrm{i}=1, \ldots, \mathrm{m})$ and criterions $C_{j}(\mathrm{j}=1, \ldots, \mathrm{n})$ into consideration, the decision matrix $\mathrm{D}$ can be expressed as follows:

$$
\begin{aligned}
& \begin{array}{llll}
\mathrm{C}_{1} & \mathrm{C}_{2} & \ldots & \mathrm{C}_{\mathrm{n}}
\end{array}
\end{aligned}
$$

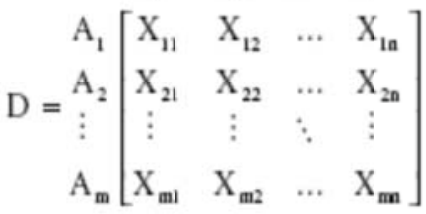

$$
\begin{aligned}
& W=\left(w_{1}, w_{2}, \ldots, w_{n}\right)
\end{aligned}
$$

Given the weighting vector $\mathrm{W}$ and decision matrix $\mathrm{D}$ with $X_{i j}$ elements, the objective of the problem is to rank all the alternatives by giving each of them an overall utility with respect to all selection criteria. The decision matrix as well as the weighting vector is originally expressed in terms of linguistic variables by decision makers. Using the triangular fuzzy numbers given in tables 1 and 2, the equivalent tables of decision making and weight vector can be developed.

\section{Step 2: Normalization of decision matrix}

Before we can make any use of data provided in step 1 we need to develop a normalized decision matrix. Doing so, we convert all incommensurable criterions into unique and common sense numbers. The decision matrix must first be normalized so that the elements will be unit-free. The structure of the normalized matrix for the k-th decision maker can be expressed as follows:

$$
R^{k}=\left[r_{i j}^{k}\right]_{m x n} \quad \mathrm{k}=1,2, \ldots, \mathrm{K} ; \mathrm{i}=1,2, \ldots, \mathrm{m} ; \mathrm{j}=1, \ldots, \mathrm{n}
$$

Where $r_{i j}^{k}$ is the normalized value of $f_{i j}^{k}=\left(a_{i j}, b_{i j}, c_{i j}\right)$ which is calculated by the following formula:

$$
r_{i j}=\left(\frac{a_{i j}}{c_{j}^{*}}, \frac{b_{i j}}{c_{j}^{*}}, \frac{c_{i j}}{c_{j}^{*}}\right)
$$

Where $c_{j}^{*}=\max _{i}\left\{c_{i j}\right\}$ and $\mathrm{j}$ belong to the benefit criterions. On the other hand when $\mathrm{j}$ belongs to the cost criterion the normalized value is calculated according to following formula: 


$$
r_{i j}=\left(\frac{a_{j}^{-}}{c_{i j}}, \frac{a_{j}^{-}}{b_{i j}}, \frac{a_{j}^{-}}{a_{i j}}\right)
$$

and $a_{j}^{-}=\min _{i}\left\{a_{i j}\right\}$.

\section{Step 3: Weighted normalized decision matrix}

In this step, the weighted normalized decision matrix for the kth decision maker needs to be constructed using the formula given below:

$$
V^{k}=\left[v_{i j}^{k}\right]_{m \times n} \quad \mathrm{k}=1,2, \ldots, \mathrm{K} ; \mathrm{i}=1,2, \ldots, \mathrm{m} ; \mathrm{j}=1, \ldots, \mathrm{n}
$$

Where,

$$
\begin{aligned}
& v_{i j}^{k}=r_{i j}^{k}(x) w_{j}^{k} \\
& v_{i j}^{k}=\left(v_{i j 1}, v_{i j 2}, v_{i j 3}\right)
\end{aligned}
$$

\section{Step 4: Distances from positive ideal and negative ideal points}

Two ideal solutions points known as positive ideal and negative ideal solution points are of highly concerned in the decision making process. The decision maker feels to stay away as far as possible from the negative ideal solution point and as close as possible to the positive ideal point. Although, these solution points are unreachable in reality they are of very concern and important to the decision maker. Therefore, the positive ideal solution shown by $A^{+}$and negative ideal point shown by $A^{-}$is determined as follows:

$$
\begin{aligned}
& A^{+}=\left(v_{1}^{+}, v_{2}^{+}, \ldots, v_{n}^{+}\right) \\
& A^{-}=\left(v_{1}^{-}, v_{2}^{-}, \ldots, v_{n}^{-}\right)
\end{aligned}
$$

Where

$$
\begin{aligned}
& v_{j}^{+}=\max _{i}\left\{v_{i j 3}\right\} \\
& v_{j}^{-}=\min _{i}\left\{v_{i j 1}\right\}
\end{aligned}
$$

The distances from the positive ideal solution and negative ideal solution point are calculated according to following formula, respectively:

$$
d_{i}^{K+}=\sum_{j=1}^{n} d\left(v_{i j}^{K}, v_{j}^{+}\right)
$$




$$
d_{i}^{K-}=\sum_{j=1}^{n} d\left(v_{i j}^{K}, v_{j}^{-}\right)
$$

\section{Step 5: Overall distance from positive ideal and negative ideal points}

To derive group preferences provided by multiple decision makers and combine the group synthesis and prioritization stages into a single integrated stage, the geometric mean with the modified TOPSIS approach is employed. The overall separation measure is calculated as:

$$
\begin{aligned}
& d_{i}^{-+}=\left(\prod_{k=1}^{K} d_{i}^{k+}\right)^{1 / k} \quad \mathrm{i}=1,2, \ldots, \mathrm{m} \\
& d_{i}^{--}=\left(\prod_{k=1}^{K} d_{i}^{k-}\right)^{1 / k} \quad \mathrm{i}=1,2, \ldots, \mathrm{m}
\end{aligned}
$$

\section{Step 6: Relative closeness to the ideal}

The relative closeness of the alternative $A_{i}$ with respect to the ideal solution $\mathrm{A}+$ is defined as:

$$
C_{i}^{-}=\frac{d_{i}^{--}}{d_{i}^{-+}+d_{i}^{--}}
$$

\section{Step 7: Rank the alternatives}

A set of alternatives can now be preference ranked according to the descending order of $C_{i}^{-}$, and the one with the maximum value of $C_{i}^{-}$is the best.

\section{Case study}

For various reasons firms are reluctant to adopt RFID as a part of their internal systems. This is because of uncertainty regarding the payoff that will (or might) result from the adoption ${ }^{[64,65]}$. Central to this uncertainty are risks accompanying adoption that can be grouped into two broad areas - uncertainty with regard to the requirements and capabilities of the technology itself and uncertainty with regard to the effects of the technology on inter-organizational relationships ${ }^{66]}$. Due to the fact that at the present time RFID is still in its early stages of development and acceptance, by the management of large and small companies, there are large numbers of questions that are unanswered with regard to its actual or potential use.

RFID adoption could become a big issue in some companies. This means 100\% acceptance of RFID or its step by step acceptance that means using a combination of RFID and barcode technologies. It is obvious enough that all subsidiaries and warehouses of a company can not accept and implement RFID technology into their management system at the same time. Hence, going hand to hand and planning to use RFID in stages could be an attractive idea. Although, some managements are running to find opportunities for implementing RFID in their organizations others are conscious and walk firmly and try not to come into a conclusion overnight. Management's acceptance of RFID usefulness and their true initiation for having such a system in their organization is not a simple task and demands a great deal of efforts for selling such an idea by the internal IT team to them. 
Hou and Huang ${ }^{[7]}$ pointed that: RFID central promise is that it is a more level playing field with respect to the ability to coordinate material flows. This means that, with RFID the difference in coordinating capabilities between the previously "qualified" and the previously "unqualified" is expected to diminish substantially over time. If an industry exhibits scarcity with respect to "qualified" suppliers, then, it is likely that there will be substantial pressure placed on the "non-qualified" within that industry to adopt this scarcity-reducing technology ${ }^{[67,68]}$. This all means that if one company does not accept the new technology at the early stages of its introduction it has to accept it sometimes in the near future. This is an external organizational force applied by the industry itself to straighten the non-accepted technology organization. Since this is an obvious fact for some of those big companies, what they prefer to do is going stage by stage and introduce that technology as a pilot in one portion of the company and then finally to the whole system.

Sometimes, the nature of the business forces the company to accept the technology rather faster than other industries. For units whose traceability is vitally important - medical products, safety-related components - the resource dependence theory would predict even more rapid RFID adoption, since its ability to reduce "qualified” suppliers' bargaining power can be expected to be particularly strong ${ }^{[69]}$. It results from the combined effect of two factors: (1) the nature of scarcity and (2) the relative ease with which RFID enables traceability. However, this type of business may also accept the technology stage by stage.

With the analysis performed from the articles above it is concluded that the most appropriate types of alternatives that should be taken into consideration are those that relates RFID systems and barcode systems together. This is because of the power of the barcode and its popularity at the present time. Barcode is going to stay for a long time and will not disappear overnight. This is because the barcode system is less expensive to setup, manage, work with, and it is in use all around the world. Hence, this research is up to putting to vote the following RFID-based-mixed-systems as alternative to the team of decision makers:

1) System type 1: a system with 20 percent RFID power and $80 \%$ barcode capability

2) System type 2: a system with 30 percent RFID power and 70\% barcode capability

3) System type 3: a system with 40 percent RFID power and 60\% barcode capability

4) System type 4: a system with 50 percent RFID power and 50\% barcode capability

5) System type 5: a system with 60 percent RFID power and 40\% barcode capability

This means stage by stage conversion from barcode system into the RFID-based system which gives sufficient time to both producers and consumers to prepare their own RFID-based system for service. The criterions that are of the highest preference to most management through the entire industries are:

1) The hardware and software costs

2) The contribution that system can have on the organization

3) Changing the current situation for a better one

4) Expert reliability on the RFID-based system support

In this section, a system selection problem is under review where the most appropriate one need to be identified using a group of three decision makers of DM1, DM2, and DM3. For this purpose, a list containing five RFID-based systems (see Table 3) are determined, related criterions are identified and passed to a team of three decision makers. Each decision maker identifies the importance level of each criterion using the fuzzy linguistic terms given in table 1 . To determine the decision matrix, the fuzzy linguistic terms provided in table 2 are used by the decision makers. More details on the criterions used and the alternative systems under study are given below. Linguistic terms and fuzzy numbers used in the following sections are those provided in tables 1 and 2. 


\subsection{Alternative systems}

Five RFID-based systems starting with a system of 20 percent RFID and $80 \%$ barcode features and ending with a system of $60 \%$ RFID and $40 \%$ barcode features are under consideration here (see Table 3 ).

Table 3. Features of five alternative systems

\begin{tabular}{lll}
\hline Alternatives & RFID-based systems & Barcode based system \\
\hline System 1 (A1) & $20 \%$ & $80 \%$ \\
System 2 (A2) & $30 \%$ & $70 \%$ \\
System 3 (A3) & $40 \%$ & $60 \%$ \\
System 4 (A4) & $50 \%$ & $50 \%$ \\
System 5 (A5) & $60 \%$ & $40 \%$ \\
\hline
\end{tabular}

\subsection{Criterions}

The criterions used in this study are:

1) The hardware and software costs (C1)

2) The contribution that system can have on the organization (C2)

3) Changing the current situation for a better one (C3)

4) Expert reliability on the RFID-based system support (C4)

\subsection{Criterion classification}

These four criterions can be classified into two categories of benefit type and cost type as shown below:

$$
\begin{aligned}
& \mathrm{B}=\left\{\begin{array}{l}
\text { Benefit } \\
\text { Type } \\
\text { criterion }
\end{array}\right\}=\{\text { Contribution, Level of change, Expert reliability }\} \\
& \mathrm{C}=\left\{\begin{array}{l}
\text { Cost } \\
\text { Type } \\
\text { Criterion }
\end{array}\right\}=\{\text { Costs of hardware and software }\}
\end{aligned}
$$

\subsection{Solution details and discussion}

Three decision makers DM1, DM2, and DM3 form a committee to act as decision makers in this case study. Each decision maker uses their own judgment to determine the level of importance of each of the criterion with respect to the evaluations that they want to determine.

Table 4. Level of importance of each criterion

\begin{tabular}{llll}
\hline Criterions & Decision maker 1 (DM1) & Decision maker 2 (DM2) & Decision maker 3 (DM3) \\
\hline Cost of H\&S (C1) & $\mathrm{VH}$ & $\mathrm{H}$ & $\mathrm{MH}$ \\
Contributions (C2) & $\mathrm{H}$ & $\mathrm{VH}$ & $\mathrm{VH}$ \\
Level of change (C3) & $\mathrm{MH}$ & $\mathrm{MH}$ & $\mathrm{H}$ \\
Expert reliability (C4) & $\mathrm{H}$ & $\mathrm{VH}$ & $\mathrm{VH}$ \\
\hline
\end{tabular}

Next, it was asked the decision maker committee to rate systems (alternatives) with respect to the criterion that is identified for the evaluation purposes. The results of their effort are summarized in the table given below: 
Table 5. Decision makers rating of alternatives with respect criterions

\begin{tabular}{|c|c|c|c|c|c|}
\hline Decision makers & Alternatives & $\begin{array}{l}\text { Costs of H\&S } \\
\text { (C1) }\end{array}$ & $\begin{array}{l}\text { Contribution } \\
\text { (C2) }\end{array}$ & Level of Change (C3) & Expert reliability (C4) \\
\hline \multirow[t]{5}{*}{ DM 1} & System 1 & $\mathrm{P}$ & VG & VG & MP \\
\hline & System 2 & $\mathrm{P}$ & VG & G & MP \\
\hline & System 3 & MP & G & G & MP \\
\hline & System 4 & $\mathrm{~F}$ & MG & MG & F \\
\hline & System 5 & MG & MG & MG & $\mathrm{F}$ \\
\hline \multirow[t]{5}{*}{ DM 2} & System 1 & $\mathrm{P}$ & G & VG & $\mathrm{P}$ \\
\hline & System 2 & $\mathrm{P}$ & G & VG & MP \\
\hline & System 3 & MP & MG & G & MP \\
\hline & System 4 & $\mathrm{~F}$ & MG & $\mathrm{F}$ & $\mathrm{F}$ \\
\hline & System 5 & MG & $\mathrm{F}$ & $\mathrm{F}$ & $\mathrm{F}$ \\
\hline \multirow[t]{5}{*}{ DM 3} & System 1 & $\mathrm{P}$ & $\mathrm{MP}$ & MG & $\mathrm{P}$ \\
\hline & System 2 & $\mathrm{P}$ & $\mathrm{F}$ & MG & $\mathrm{P}$ \\
\hline & System 3 & $\mathrm{~F}$ & MG & $\mathrm{F}$ & $\mathrm{P}$ \\
\hline & System 4 & MG & G & $\mathrm{F}$ & MP \\
\hline & System 5 & G & G & $\mathrm{F}$ & MP \\
\hline
\end{tabular}

The decision matrix D with $x_{i j}$ elements is given by table 6 .

Table 6. Decision matrix

\begin{tabular}{lllll}
\hline & Benefits & Change & Reliability & Costs \\
\hline & $(0.20,0.35,0.5)$ & $(0.50,0.65,0.80)$ & $(0.05,0.2,0.35)$ & $(0.05,0.2,0.35)$ \\
$X_{i j}$ & $(0.35,0.50,0.65)$ & $(0.50,0.65,0.80)$ & $(0.05,0.2,0.35)$ & $(0.05,0.2,0.35)$ \\
& $(0.50,0.65,0.80)$ & $(0.35,0.50,0.65)$ & $(0.05,0.20,0.35)$ & $(0.35,0.50,0.65)$ \\
& $(0.65,0.80,0.95)$ & $(0.35,0.5,0.65$ & $(0.20,0.35,0.50)$ & $(0.50,0.65,0.80)$ \\
& $(0.65,0.80,0.35)$ & $(0.35,0.50,0.65)$ & $(0.2,0.35,0.5)$ & $(0.65,0.80,0.95)$ \\
\hline
\end{tabular}

Table 7. weighted normalized decision matrix

\begin{tabular}{lllll}
\hline & Benefits & Change & Reliability & Costs \\
\hline & $(0.17,0.37,0.53)$ & $(0.34,0.55,0.80)$ & $(0.04,0.21,0.37)$ & $(0.07,0.16,0.8)$ \\
& $(0.29,0.53,0.68)$ & $(0.34,0.55,0.80)$ & $(0.04,0.21,0.37)$ & $(0.07,0.16,0.8)$ \\
$V_{i j}$ & $(0.42,0.68,0.84)$ & $(0.24,0.42,0.65)$ & $(0.04,0.21,0.37)$ & $(0.04,0.07,0.11)$ \\
& $(0.55,0.84,1)$ & $(0.24,0.42,0.65)$ & $(0.17,0.37,0.53)$ & $(0.03,0.05,0.08)$ \\
& $(0.55,0.84,1)$ & $(0.24,0.42,0.65)$ & $(0.17,0.37,0.53)$ & $(0.03,0.04,0.06)$ \\
\hline
\end{tabular}

Table 8. Distance from positive and negative solution points by DM

\begin{tabular}{lcccccccc}
\hline \multirow{2}{*}{ Alternatives } & DM1 & DM1 & & DM2 & DM2 & & DM3 & DM3 \\
\cline { 2 - 9 } & $d^{1-}$ & $d^{1+}$ & & $d^{2-}$ & $d^{2+}$ & & $d^{3-}$ & $d^{3+}$ \\
\hline A1 & 1.680 & 1.463 & A1 & 1.740 & 1.543 & A1 & 1.296 & 1.786 \\
A2 & 1.614 & 1.535 & A2 & 1.866 & 1.415 & A2 & 1.429 & 1.648 \\
A3 & 1.105 & 1.200 & A3 & 1.256 & 1.191 & A3 & 1.061 & 1.220 \\
A4 & 0.951 & 1.214 & A4 & 1.146 & 1.179 & A4 & 1.317 & 0.963 \\
A5 & 0.923 & 1.186 & A5 & 0.994 & 1.278 & A5 & 1.305 & 0.951 \\
\hline
\end{tabular}


Table 9. Combined distances by alternatives

\begin{tabular}{llll}
\hline Alternatives & $d^{1-}$ & $d^{1+}$ & Sum \\
\hline A1 & 1.263 & 1.344 & 2.607 \\
A2 & 1.435 & 1.194 & 2.629 \\
A3 & 0.491 & 0.581 & 1.072 \\
A4 & 0.478 & 0.459 & 0.937 \\
A5 & 0.399 & 0.480 & 0.879 \\
\hline
\end{tabular}

Table 10. relative closeness to the ideal solution by alternatives

\begin{tabular}{lllll}
\hline Alternatives & $d^{1-}$ & Sum & CCI & Ranking \\
\hline A1 & 1.263 & 2.607 & 0.4844 & 3 \\
A2 & 1.435 & 2.629 & 0.5459 & 1 \\
A3 & 0.491 & 1.072 & 0.4580 & 4 \\
A4 & 0.478 & 0.937 & 0.5101 & 2 \\
A5 & 0.399 & 0.879 & 0.4536 & 5 \\
\hline
\end{tabular}

From table 10 we conclude that A2 > A4 > A1 > A3 > A5. This means that an RFID-based system having 30\% RFID feature and $70 \%$ barcode feature are the most appropriate one as far as these groups of three decision makers are concerned. Due to the facts that human judgments change from one decision maker to another therefore another group of decision makers may reach to a different set of solution.

\section{Conclusion}

RFID adoption could become a big issue in some companies. This means 100\% acceptance of RFID or its step by step acceptance that means using a combination of RFID and barcode technologies. It is obvious enough that all subsidiaries and warehouses of a company can not accept and implement RFID technology into their management system at the same time. Hence, going hand to hand and planning to use RFID in stages could be an attractive idea. Although, some managements are running to find opportunities for implementing RFID in their organizations others are conscious and walk firmly and try not to come into a conclusion overnight. Management's acceptance of RFID usefulness and their true initiation for having such a system in their organization is not a simple task and demands a great deal of efforts for selling such an idea by the internal IT team to them.

Generally speaking, the selection of right RFID-based system is not a simple task. This is because the money to be invested and the success of the company in the long run are the issues. The acceptance of RFID-based system is impacted by a number of factors that each plays a very significant role in the success of the company. Although management is the key thinker in the technology selection and implementation there are always several experts from different parts of the organization that are involved in the selection of new technology and its enforcement. Considering that, a group of managements are those who make decisions on the employment of new technology and its implementation and success as well.

This paper presents an extension of the TOPSIS approach of Hwang and Yoon for the RFID-based system selection problem for the reasons given below: (1) a sound logic that represents the rational of human choice; (2) a scalar value that accounts for both the best and worst alternative simultaneously; (3) a simple computation process that can be easily programmed into a spreadsheet and computer codes as well; and (4) the performance measures of all alternatives on attributes can be visualized on a polyhedron, at least for any two dimensions (Shih, Syur,\& Lee, 2007). 


\section{References}

[1] E. Fleisch, C. Tellkamp, Inventory accuracy and supply chain performance: simulation study of a retail supply chain.International Journal of Production Economics. 2005; 95 (3): 373-385. http://dx.doi.org/10.1016/j.ijpe.2004.02.003

[2] Atali, A., H. Lee, O. Ozer, If the inventory manager knew: value of RFID under imperfect inventory information.Working Paper, Stanford University, 2005.

[3] H. Lee, O. Ozer, Unclocking the value of RFID. Working Paper, Stanford University, 2005.

[4] A.G. De Kok, K.H. van Donselaar, T. van Woensel, A break-even analysis of RFID technology for inventory sensitive to shrinkage, Int. J. Production Economics. 2008; 112: 521-531. http://dx.doi.org/10.1016/j.ijpe.2007.05.005

[5] Thysen, Agriculture in the information society. J. Agric. Eng. Res. 2000; 76: 297-303. http://dx.doi.org/10.1006/jaer.2000.0580

[6] J.L., Hou, and C.H. Huang, Quantitative performance evaluation of RFID applications in the supply chain of the printing industry, Industrial Management and Data Systems. 2006; 106: 96-120. http://dx.doi.org/10.1108/02635570610641013

[7] Y. Zare Mehrjerdi, RFID-enabled Systems: a brief review, International Journal of Assembly Automation, 2008.

[8] Y. Zare Mehrjerdi, RFID and its Benefits: a multiple Case analysis, International Journal of Assembly Automation. 2011; 31(3): 251-262. http://dx.doi.org/10.1108/01445151111150596

[9] M. Roberti, RFID: the cost of being smart. CIO insights 1 (30), September 1. URL: www.cioinsight.com/previous/issues, 2003

[10] L. Sullivan, Wal-Mart assesses new uses for RFID. Information Week, March 28. URL: www,informationweek.com/thisweek/02-28-2005

[11] L. Sullivan, Dunn, D., Vendors warn of RFID tag shortage in coming months. Information week, October 11. URL: www. informationweek.com/thisweek/10-11-2004.Systems, Vol. 50, p. 247.

[12] J. Collins, Estimating RFID pace of adoption. RFID Journal, 2003.

[13] J. Collins “'Reading Books reduces out-of-stocks”, RFID Journal. Available from: www.rfidjournal.com/article/articleview/2696/, 2006

[14] J. Rappold, 2003. The risks of RFID, Industrial Engineer: IE. 2003; 35(11): 37-38.

[15] C.K.M. Lee, Ho, W., Ho, G.T.S., and Lau, H.C.W., Design and development of logistics workflow systems for demand management with RFID, Expert systems with applications. 2011; 38: 5428-5437. http://dx.doi.org/10.1016/j.eswa.2010.10.012

[16] J.M. Ko, Kwak C., Cho Y., Kim C.O., Adaptive product tracking in RFID-enabled large-scale supply chain, Expert systems with applications. 2011; 38: 1583-1590. http://dx.doi.org/10.1016/j.eswa.2010.07.077

[17] J.G. Szmerekovsky, Tilson V., Zhang, J., Analytical model of adoption of item level RFID in a two-echelon supply chain with shelf-space and price-dependent demand, Decision support systems. 2011; 51: 833-841. http://dx.doi.org/10.1016/j.dss.2011.02.002

[18] Ustundag, Serdar Kilinc M., and Cevikcan E., Fuzzy rule-based system for the economic analysis of RFID investments, Expert systems with applications. 2010; 37: 5300-5306. http://dx.doi.org/10.1016/j.eswa.2010.01.009

[19] G. Legg, RFID tags connect smart cars to smart highways, EDN. 1994;39 (26): 33-34.

[20] R. Schneirman. RFID markets growth tied to new applications. Microwaves \&RF. 1995: pp.10-11.

[21] A.L. Naresh, and C.T. Jahern, Communication and tracking for construction vehicles, Journal of Construction Engineering and Management, ASCE. 1997; 123: 261-268. http://dx.doi.org/10.1061/(ASCE)0733-9364(1997)123:3(261)

[22] W. Labs, New scanners, RFID systems help manufacturers keep tracks of products in the marking. Instrumentation and Control Systems. 1998; 71: 80.

[23] G. Heftman, RFID technologies put zip in the mail, Microwaves \& RF. 1998; 37: 41.

[24] L.C. Wang, Y.C. Lin and P.H. Lin, Dynamic mobile RFID-based supply chain control and management system in construction, International Journal of Advanced Engineering Informatics-Special Issue on RFID Applications in Engineering, 2006.

[25] D. Lin, Barton, R., Bi, H., Freimer, M., Challenges in RFID enabled supply chain management. Quality Progress. 2006 ; $39: 23-28$.

[26] Naim, “A supply chain diagnostic methodology—determining the vector of change”, Computers and Industrial Engineering. 2002; 43: 135-157. http://dx.doi.org/10.1016/S0360-8352(02)00072-4

[27] L.S. Lee, Kirk DF, and Jeffery SS, Radio frequency identification (RFID) implementation in the service sector: a customer-facing diffusion model. International Journal of Production Economics, 2007.

[28] P. Repo, M. Kerttula, M. Salmela and H. Huomo, Virtual product design case study: The Nokia RFID tag reader, IEEE Pervasive Computing. 2005; 4 (4): 95-99. http://dx.doi.org/10.1109/MPRV.2005.92

[29] E.W.T. Ngai, Moon, K.K.L., Riggins, F.J., and Candace, Y.Y.I., RFID research: an academic literature review (1995-2005) and future research directions. International journal of Production Control, 2007. 
[30] S.F. Wamba, Y. Bendavid, L.A. Lefebvre and E. Lefebvre., RFID technology and the EPC network as enablers of mobile business: a case study in a retail supply chain, International Journal of Networking and Virtual Organizations. 2006 ; 3: $450-462$. http://dx.doi.org/10.1504/IJNVO.2006.011872

[31] S.F. Wamba, Lefebvre, L.A., Bendavid, Y., and Lefebvre, E., "Exploring the impact of RFID technology and the EPC network on mobile B2B ecommerce: a case study in the retail industry”, International Journal of Production Control, 2007.

[32] R. Hall, and Hampl, J.S. "Radio frequency identification applications for dietetics professionals”, Journal of the American Dietitic Association. 2004; 104: 1521-1522. PMid:15389403 http://dx.doi.org/10.1016/j.jada.2004.08.012

[33] Adams, Pharmaceutical manufacturing: RFID - reducing errors and effort, Filtration and Separation. 2007; 44: 17-19. http://dx.doi.org/10.1016/S0015-1882(07)70179-9

[34] J.A. Fisher, and Monahan, T., Tracking the social dimensions of RFID systems in hospitals. International journal of Medical Informatics. 2008; 77: 176-183. PMid:17544841 http://dx.doi.org/10.1016/j.ijmedinf.2007.04.010

[35] H.K.H. Chow, Choy, K.L., and Lee, W.B., “A dynamic logistics process knowledge-based system - An RFID multi-agent approach”, Knowledge based Systems. 2007; 20: 357-372. http://dx.doi.org/10.1016/j.knosys.2006.08.004

[36] Estefania, Stefano, Z., and Santiago, M., et al., "Flexible tag Microlab development: gas sensors integration in RFID flexible tags for food logistics”, Sensors and Actuators B, Chemical. 2007; 127: 2-7. http://dx.doi.org/10.1016/j.snb.2007.07.007

[37] W.M.G. Wismans, Identification and registration of animals In the European Union, Computers and Electronics in Agricultures. 1999; 24:.99-108. http://dx.doi.org/10.1016/S0168-1699(99)00040-X

[38] Y. Zare Mehrjerdi Operations Research a Profit Making Tool, LAP Lambert Academic Publishing, Germany, 2012.

[39] G. Zhang. and Lu, J., “An integrated group decision-making method dealing with fuzzy preferences for alternatives and individual judgments for selection criteria”, Group Decision and Negotiation. 2003; 12: 501-15. http://dx.doi.org/10.1023/B:GRUP.0000004197.04668.cf

[40] C.T. Chen, Extensions of the TOPSIS for group decision-making under fuzzy environment. Fuzzy Sets and Systems. 2000; 114: 1-9. http://dx.doi.org/10.1016/S0165-0114(97)00377-1

[41] C.T. Chen, Lin, C.T. and Huang, S.F., “A fuzzy approach for supplier evaluation and selection in supply chain management”, International Journal of Production Economics. 2006; 102: 289-301. http://dx.doi.org/10.1016/j.ijpe.2005.03.009

[42] M.S. Kuo, Tzeng, G. H., \& Huang, W. C. Group decision-making based on concepts of ideal and anti-ideal points in a fuzzy environment. Mathematical and Computer Modeling. 2007; 45: 324-339. http://dx.doi.org/10.1016/j.mcm.2006.05.006

[43] C. Kahraman, Ates, N.Y., C, evik, S. and Gu“lbay, M., "Fuzzy multi-attribute cost-benefit analysis of e-services”, International Journal of Intelligent Systems. 2007; 22: 547-65. http://dx.doi.org/10.1002/int.20213

[44] D.S. Negi, Fuzzy analysis and optimization. PhD thesis. Department of Industrial Engineering, Kansas State University, 1989.

[45] S.J. Chen and Hwang, C. L., Fuzzy multiple attribute decision making. Berlin: Springer, 1992. http://dx.doi.org/10.1007/978-3-642-46768-4

[46] M.F. Chen and G.H. Tzeng, Combining grey relation and TOPSIS concepts for selecting an expatriate host country, Mathematical and Computer Modeling. 2004; 40: 1473-1490. http://dx.doi.org/10.1016/j.mcm.2005.01.006

[47] G.R. Jahanshahloo, Hosseinzadeh Lotfi, F., \& Izadikhah, M., Extension of the TOPSIS method for decision-making problems with fuzzy data. Applied Mathematics and Computation. 2006; 181: 1544-1551. http://dx.doi.org/10.1016/j.amc.2006.02.057

[48] G.S. Liang, Fuzzy MCDM based on ideal and anti-ideal concepts. European Journal of Operational Research. 1999; 112 : 682-691. http://dx.doi.org/10.1016/S0377-2217(97)00410-4

[49] Y.M. Wang and Elhag, T. M. S., On the normalization of interval and fuzzy weights. Fuzzy Sets and Systems. 2006; 157: 24562471. http://dx.doi.org/10.1016/j.fss.2006.06.008

[50] Y.J. Wang and Lee, H. S., Generalizing TOPSIS for fuzzy multiple-criteria group decision-making. Computers and Mathematics with Applications. 2007; 53: 1762-1772. http://dx.doi.org/10.1016/j.camwa.2006.08.037

[51] Y.M. Wang, Luo, Y., \& Hua, Z. S., A note on group decision-making based on concepts of ideal and anti-ideal points in a fuzzy environment. Mathematical and Computer Modeling. 2007; 46: 1256-1264. http://dx.doi.org/10.1016/j.mcm.2007.01.003

[52] C.H. Yeh, Deng, H., Chang, Y. H., Fuzzy multi criteria analysis for performance evaluation of bus companies. European Journal of Operational Research. 2000; 126: 459-473. http://dx.doi.org/10.1016/S0377-2217(99)00315-X

[53] C.H. Yeh, \& Deng, H., A practical approach to fuzzy utilities comparison in fuzzy multi criteria analysis. International Journal of Approximate Reasoning. 2004; 35: 179-194. http://dx.doi.org/10.1016/j.ijar.2003.09.002

[54] Y. Zare Mehrjerdi, Hierarchical Multi-Criteria Risk-Benefit Analysis in Fuzzy Environment, Applied Soft Computing, (2012a)

[55] Y. Zare Mehrjerdi, Multi-Criteria Risk-Benefit Analysis of Healthcare Management, International journal of Industrial Engineering and Production Research, 2012b (accepted)

[56] H. Deng, Yeh, C. H., \& Willis, R. J., Inter-company comparison using modified TOPSIS with objective weights. Computers and Operations Research. 2000; 27: 963-973. http://dx.doi.org/10.1016/S0305-0548(99)00069-6 
[57] S.H. Tsuar, Chang, T. Y., \& Yen, C. H., Evaluation of airline service quality by fuzzy MCDM. Tourism Management. 2002; 23: 107-115. http://dx.doi.org/10.1016/S0261-5177(01)00050-4

[58] D.H. Jee and Kang, K.J., “A method for optimal material selection aided with decision making theory”, Materials \& Design. 2000; 21: 199-206. http://dx.doi.org/10.1016/S0261-3069(99)00066-7

[59] K. Yoon and Hwang, C.L., "Manufacturing plant location analysis by multiple attribute decision making: Part I - single plant strategy”, International Journal of Production Research. 1985; 23(2): 345-59. http://dx.doi.org/10.1080/00207548508904712

[60] K.P. Yoon and Hwang, C.L., Multiple Attribute Decision Making: An Introduction, 1995.

[61] Parkan, C. and Wu, M., "Decision-making and performance measurement models with applications to robot selection”, Computers \& Industrial Engineering. 1999; 36: 503-23. http://dx.doi.org/10.1016/S0360-8352(99)00146-1

[62] L.A. Zadeh, Fuzzy sets. Information and Control. 1965; 8: 338-353. http://dx.doi.org/10.1016/S0019-9958(65)90241-X

[63] C.L. Hwang and Yoon, K., Multiple Attribute Decision Making Methods and Applications, Springer, New York, NY, 1981. http://dx.doi.org/10.1007/978-3-642-48318-9

[64] P.M. Reyes, Gimenez Thomsen, C., Frazier, G.V., RFID attractiveness in the US and Spanish Grocery chains: an exploratory study. CEMS Research Seminar Proceedings, 2006.

[65] Dutta, Lee, H.L. and Whang, S., "RFID and operations management: technology, value and incentives", Production and Operations Management. 2007; 16(5): 646-55. http://dx.doi.org/10.1111/j.1937-5956.2007.tb00286.x

[66] A.L. Cannon, Reyes, P.M., Frazier, G.V., Prater, E.L., RFID in the contemporary supply chain: multiple perspectives on its benefits and risks, International journal of operations and production management. 2008; 28.

[67] E. Sahin, Dallery, Y., Gershwin, S., Performance evaluation of a traceability system: an application to the radio frequency identification technology. In: Proceedings of the 2002 IEEE International Conference on Systems, Man and Cybernetics. Yasmine Hammamet, Tunisia. 2002: 3: 647-650.

[68] T. Metty, T., Harlan, R., Samuelson, Q., Moore, T., Morris, T., Sorensen, R., Schneur, A., Raskina, O., Schneur, R., Kanner, J., Potts, K. and Robbins, J., “Reinventing the supplier negotiation process at Motorola”, Interfaces. 2005; 35: 7-23. http://dx.doi.org/10.1287/inte.1040.0119

[69] R. Caves and Porter, M., "From entry barriers to mobility barriers: conjectural decisions and contrived deterrence to new competition”, Quarterly Journal of Economics. 1977; 91: 241-62. http://dx.doi.org/10.2307/1885416

[70] H.S. Shih, Syur, H. J., \& Lee, E. S., An extension of TOPSIS for group decision making. Mathematical and Computer Modeling. 2007; 45: 801-813. http://dx.doi.org/10.1016/j.mcm.2006.03.023 